\title{
Orientation dependence of the deformation microstructure in compressed aluminum
}

\author{
Le, G.M.; Godfrey, A.; Hong, Chuanshi; Huang, Xiaoxu; Winther, Grethe
}

Published in:

Scripta Materialia

Link to article, DOI:

10.1016/j.scriptamat.2011.11.034

Publication date:

2012

Document Version

Early version, also known as pre-print

Link back to DTU Orbit

Citation (APA):

Le, G. M., Godfrey, A., Hong, C., Huang, X., \& Winther, G. (2012). Orientation dependence of the deformation microstructure in compressed aluminum. Scripta Materialia, 66(6), 359-362.

https://doi.org/10.1016/j.scriptamat.2011.11.034

\section{General rights}

Copyright and moral rights for the publications made accessible in the public portal are retained by the authors and/or other copyright owners and it is a condition of accessing publications that users recognise and abide by the legal requirements associated with these rights.

- Users may download and print one copy of any publication from the public portal for the purpose of private study or research.

- You may not further distribute the material or use it for any profit-making activity or commercial gain

- You may freely distribute the URL identifying the publication in the public portal

If you believe that this document breaches copyright please contact us providing details, and we will remove access to the work immediately and investigate your claim. 
TITLE PAGE

\section{Orientation dependence of the deformation microstructure in compressed}

\section{aluminum}

GM Le ${ }^{1}$, A. Godfrey ${ }^{1}$, CS Hong $^{2}$, X Huang ${ }^{2}$, G Winther $^{2}$

${ }^{a}$ Laboratory for Advanced Materials, Dept. Materials Science and Engineering, Tsinghua University, Beijing 100084, China

${ }^{\mathrm{b}}$ Danish-Chinese Center for Nanometals, Materials Research Division, Ris $\varnothing$ National Laboratory for Sustainable Energy, Technical University of Denmark, DK-4000 Roskilde, Denmark.

\section{Corresponding author details:}

Prof. A. Godfrey, Dept. Materials Science and Engineering, Tsinghua University, Beijing, 100084, China. Tel: +8610 62788317; Fax. +86 10 62771160; email: awgodfrey @ mail.tsinghua.edu.cn

\section{Word count}

Fig. 1: $\quad 5 \mathrm{~cm} \times 1$ column $=100$ words

Fig. 2: $\quad 6 \mathrm{~cm} \times 2$ column $\quad=\quad 240$ words

Fig. 3: $\quad 5 \mathrm{~cm} \times 2$ column $\quad=\quad 200$ words

Fig. 4: $\quad 5 \mathrm{~cm} \times 2$ column $=200$ words

total for figures $\quad=\quad 740$ words

words in text (inc. abs./refs/etc.) $=2700$ words

TOTAL $=3440$ words (3700 MAX) 


\title{
Orientation dependence of the deformation microstructure in compressed aluminum
}

\author{
GM Le ${ }^{1}$, A. Godfrey ${ }^{1}$, CS Hong ${ }^{2}$, X Huang $^{2}$, G Winther ${ }^{2}$ \\ ${ }^{a}$ Laboratory for Advanced Materials, Dept. Materials Science and Engineering, Tsinghua \\ University, Beijing 100084, China \\ ${ }^{\mathrm{b}}$ Danish-Chinese Center for Nanometals, Materials Research Division, Ris $\emptyset$ National Laboratory \\ for Sustainable Energy, Technical University of Denmark, DK-4000 Roskilde, Denmark
}

\begin{abstract}
:
The orientation dependence of the deformation microstructure has been investigated in aluminum compressed to $20 \%$ reduction. The dislocation boundaries formed can be classified, as for tension, into one of three types: dislocation cells (Type 2), and extended planar boundaries near (Type 1) or not near (Type 3) a $\{111\}$ trace. The Type 3 boundaries, however, show some clear differences to those seen in tension, suggesting differences in the dislocation interactions leading to boundary formation between tension and compression.
\end{abstract}

Key words: Dislocation boundaries; Transmission electron microscopy (TEM); Deformation structure; Aluminum.

For quite some time the flow stress after a strain path change, e.g. [1, 2], and the subsequent transient stress response, e.g. [3-5] have been investigated and attributed to interactions between the dislocation boundaries evolved during the first deformation step and dislocations from new slip systems activated after the strain path change. The occurrence of stress transients, as well as 
electron microscopy studies [6-9], imply a reorganization of the dislocation boundaries following a strain path change.

As a means to better understand such reorganizations, the boundaries evolved during tension, compression, and tension/compression tests have been investigated, revealing that the average inclination angle between the boundaries and the main deformation axis is about $30^{\circ}$ after tension as opposed to $55^{\circ}$ after compression [10]. After reversal of the strain path in tension/compression tests [10], as well as in reversed torsion tests [11], the distribution of dislocation boundary inclination angles resembles a superposition of the distributions observed before and after the strain path reversal.

Following up on studies confirming a strong orientation dependence of deformation microstructures resulting from monotonic deformation [12-14], the preferred alignment of extended planar dislocation boundaries has been studied and their crystallographic alignment has been analysed. The crystallographic boundary plane has been found to strongly depend on the crystallographic orientation of the grain in both tension [15] and rolling [13, 16]. Three main types of dislocation boundary structures are generally observed [17]: Type 1 with extended planar boundaries aligned with the most active slip planes, Type 2 with an equiaxed cell structure without extended planar boundaries and Type 3 with extended planar boundaries lying far from a slip plane. Type 3 boundaries, still align though with specific crystallographic planes, depending on the grain orientation and deformation mode. For tension, these planes are $\{135\},\{441\}$, and $\{115\}$ planes, all of which are observed for grains with the tensile axis lying within $15-20^{\circ}$ of $<111>$. 
The occurrence of the specific boundary planes depending on the grain orientation originate from an underlying dependence on the slip systems $[18,19]$. Reversal of the strain path from tension to compression is not expected to significantly change the identity of the slip systems, but only their sign. The observed differences in the macroscopic alignment of the extended planar dislocation boundaries after tension and compression imply therefore a difference also in the crystallographic alignment of the boundaries. Such a difference will mean that the sign of the slip systems, and therefore the sign of the Burgers vectors of the gliding dislocations, has a dramatic impact on the dislocation interactions leading to boundary formation. As a first step to understand these interactions the present study aims at determining the grain orientation dependence and the crystallographic alignment of boundaries formed during compression for comparison with the previously studied tensile case.

The material used in this investigation was commercially-sourced AA1200 2mm thick sheet in a $\mathrm{H} 18$ (cold-rolled) condition. Prior to compression testing the sheet was annealed at $350^{\circ} \mathrm{C}$ for 2 hours to achieve a fully recrystallized microstructure. The grain structure and texture after this annealing treatment was characterized using an Oxford Instruments-HKL electron backscatter diffraction (EBSD) system attached to a Tescan 5136XM scanning electron microscope (SEM).

The average grain size after annealing was $26 \mu \mathrm{m}$ with a recrystallization texture consisting of a combination of rolling texture orientations and cube orientations. Consequently only a few grains in the sheet have normal directions (NDs) close to $<111>$ (Fig. 1). In order therefore to produce samples containing grains with a range of compression axis (CA) directions covering the full standard unit triangle, two types of sample were cut from the annealed sheet. For the first samples square pieces of dimensions $5 \mathrm{~mm} \times 5 \mathrm{~mm}$ were cut by spark erosion from the sheet. Three such 
pieces were glued stacked together (aligned along ND) to form a rectangular sample. Uniaxial compression was applied to this sample using a Gleeble-1500 apparatus with the loading direction parallel to ND. The sample was deformed by $22 \%$ at a strain rate of $1 \times 10^{-3} \mathrm{~s}^{-1}$. A second sample was prepared by spark-erosion cutting of a small piece of material $(2 \mathrm{~mm} \times 2 \mathrm{~mm} \times$ $3 \mathrm{~mm}$ ) from the annealed sheet for compression along the rolling direction (RD) of the initial sheet. This sample was deformed by $23 \%$ at a strain rate of $1 \times 10^{-3} \mathrm{~s}^{-1}$ using the same Gleeble apparatus.

For examination of the deformation microstructure in the compressed samples thin foils containing the compression axis were prepared using a twin-jet polishing method, with the thin area taken from the center part of the compression samples. The foils were examined using a JEOL 2000FX transmission electron microscope (TEM) operated at 200kV equipped with a double-tilt holder. Local orientation measurements were made using an online semi-automatic Kikuchi-line analysis system [20]

The deformation microstructures were examined in a total of 30 grains, each with a grain size of larger than $10 \mu \mathrm{m}$. For each grain, the sample was tilted to a near two-beam diffraction (where possible to a $\mathbf{g}=<111>$ condition) to reveal clearly the dislocation structure, and the orientation of the grain was recorded. Example microstructures are shown in Fig. 2. Similar to the observations resulting from tensile deformation the majority of grains contained extended planar boundaries, whilst in some grains only cell structures were observed. An example of a typical cell structure is given in Fig. 2a for a grain with a CA direction close to [0.97,0.22,0.12]. These cell structures are similar to the Type 2 structures observed in tensile-deformed samples. 
For the grains containing extended planar boundaries two distinctive morphologies could be distinguished. In some grains the extended planar boundaries were straight and extended over a long distance (e.g. Fig. 2b), whereas in other grains the extended planar boundaries were shorter and exhibited a more wavy appearance (e.g. Fig. 2c). From tension studies it is well-known that Type 1 boundaries are straighter than Type 3 boundaries, suggesting that the former boundaries are of Type 1 and the latter of Type 3 . The main feature distinguishing between the boundary types formed during tension is, however, their crystallographic alignment: Type 1 boundaries align with the most stressed slip plane, and sometimes two sets aligned with the two most stressed slip planes are observed (i.e. $\{111\}$ planes for the case of FCC metals). In contrast Type 3 boundaries lie on other crystallographic planes, though with a fixed relationship to the most stressed slip systems. Typical structures observed following tension deformation containing Type 1, 2, and 3 boundaries are shown in Fig. 3 [21].

In order to investigate the crystallographic alignment of the extended planar boundaries formed during compression the traces of the $\{111\}$ slip planes were therefore also calculated, based on the measured grain orientation and the sample tilt angles. In addition the Schmid factors for all 12 $\{111\}<011>$ slip systems were calculated for each of the deformed grains in order to determine the slip system expected to be most active during compression deformation.

In each case it was found that the straighter extended planar boundaries were close to the trace of the most highly stressed $\{111\}$ slip plane. For the example shown in Fig,. $2 b$, taken from a grain with a CA direction near the [011] corner of the [001]-[011]-[111] unit triangle, the extended planar boundaries lie close to the trace of the (11-1) plane, which is the slip plane corresponding to the highest Schmid factor for this grain. A similar correspondence between the boundary plane 
and the trace of the slip system with the highest Schmid factor was also found for the other straight extended planar boundaries observed. Compression deformation results therefore in the formation of Type 1 boundaries with similar characteristics to those formed during tension. It is also known that Type 1 boundaries that form during tension have a small systematic deviation $\left(<10^{\circ}\right)$ from the ideal planes, with the deviation corresponding to a rotation around a specific axis in a consistent direction. The present results already show that Type 1 planes are not exactly parallel to, but close $\left(<10^{\circ}\right)$ to, the trace of the most highly stressed slip plane. A detailed study of the deviation of these boundaries to the slip plane is, however, outside the scope of the current study and will be reported in a later paper.

The remainder of the extended planar boundaries were identified as Type 3, based on the observation that these boundaries deviate by large angles to the active $\{111\}$ slip planes (see for example Fig. 2c). Although the Type 3 boundaries formed during tension do not lie close to $\{111\}$ planes, a detailed analysis has shown that they nevertheless lie on crystallographic planes related to the active slip systems $[17,18]$. For the example shown in Fig. $2 \mathrm{c}$ the traces of the crystallographic planes that have been found to be important in tensile deformation have also been calculated, and in the figure those closest to the observed extended planar boundaries are shown. It is seen that although some parts of some boundaries match these traces, the correspondence is not as clear as seen in tensile-deformed samples. The Type 3 boundaries formed during compression are therefore similar to those formed during tension in that they do not lie close to $\{111\}$ planes, though they have a more irregular (wavy) appearance and tend to lie at larger angle to the loading axis. These differences are the subject of ongoing investigations. 
Based on the observations of grains with a wide range of orientations taken from both the sample compressed along ND and the sample compressed along RD it was found that all of the dislocation structures developed during compression could be classified into one of these three types of microstructure. Of 30 grains examined in detail, the microstructure in 20 grains was classified as Type 1, with 5 grains classified as having a Type 2 microstructure, and 5 grains as having a Type 3 microstructure. The orientation dependence of the deformation microstructure in these 30 grains is shown in Fig. 4a. Grains with a Type 2 structure generally have CA directions near the [100] corner of the [100]-[110]-[111] unit triangle, whereas Type 3 grains have orientations such that the CA direction is towards the [111] corner of the unit triangle. Grains with other CA directions in general have the Type 2 structure. For comparison the orientation dependence of the deformation microstructure for tension is shown in Fig. 4b. The orientation dependence is similar for both deformation modes, though the distribution of measured orientations is different due to the opposite rotations developed during tensile and compression deformation. One grain with a CA direction after deformation near the [011] corner of the unit triangle also has the Type 3 structure. It should be recalled, however, that during compression the primary slip plane is expected to rotate toward the compression plane, and accordingly for the compression axis to rotate towards the [100]-[110] line of the unit triangle [22]. The initial orientation of this grain with a final CA direction near [110] is unknown, but as an example for a grain with an initial CA direction of [321], a rotation of $\approx 11^{\circ}$ after a compression of $20 \%$, assuming single slip deformation, can be expected. The structure observed in this grain may therefore be a reflection of an initial CA direction further towards the [111] corner of the unit triangle. 
The authors gratefully acknowledge support from the Danish National Research Foundation and the National Natural Science Foundation of China (Grant Nos. 50911130230 and 50971074) for the Danish-Chinese Center for Nanometals.

\section{References}

[1] N. Hansen, D. Juul Jensen. Acta Metall. Mater. 40 (1992) 3265.

[2] Z.J. Li, G. Winther, N. Hansen. Acta Mater. 54 (2006) 401. 
[3] D.V. Wilson, P.S. Bate. Acta Metall. Mater. 42 (1994) 1099.

[4] B. Peeters, M. Seefeldt, C. Teodosiu, S.R. Kalidindi, P. Van Houtte, E. Aernoudt. Acta Mater. 49 (2001) 1607.

[5] H. Haddadi, S. Bouvier, M. Banu, C. Maier, C. Teodosiu. Int. J. Plast. 22 (2006) 2226.

[6] E. V. Nesterova, B. Bacroix, C. Teodosiu. Metall Mater Trans A. 32 (2001) 2527.

[7] B. Peeters, B. Bacroix, C. Teodosiu, P. Van Houtte, E. Aernoudt. Acta Mater. 49 (2001) 1621.

[8] P. Cizek, F. Bai, E.J. Palmiere, W.M. Rainforth. J Microsc-Oxford. 217 (2005) 138.

[9] N.A. Sakharova, J.V. Fernandes. Mater Chem Phys. 98 (2006) 44.

[10] Q. Zhu, C.M. Sellars. Scripta Mater. 45 (2001) 41.

[11] M. Lopez Pedrosa, B. Wynne, W. Rainforth. J. Microscopy 222 (2006) 97.

[12] J.H. Driver, D.J. Jensen, N. Hansen. Acta Metall. Mater. 42 (1994) 3105.

[13] Q. Liu, D. Juul Jensen, N. Hansen. Acta Mater. 46 (1998) 5819.

[14] P. Cizek. Acta Mater. 58 (2010) 5820.

[15] X. Huang, N. Hansen. Scripta Mater. 37 (1997) 1.

[16] F. Lin, A. Godfrey, G. Winther. Scripta Mater. 61 (2009) 237.

[17] X. Huang, G. Winther. Phil. Mag. 87 (2007) 5189.

[18] G. Winther, X. Huang. Phil. Mag. 87 (2007) 5215.

[19] G. Winther. Acta Mater. 56 (2008) 1919.

[20] Q. Liu. Ultramicroscopy 60 (1995) 81. 
[21] N. Hansen, X. Huang. Acta Mater. 46 (1998) 1827.

[22] W.F. Hosford. The mechanics of crystals and textured polycrystals, Oxford University Press, New York-Oxford 1993.

[23] C. Buque, J. Bretschneider, A. Schwab, C. Holste. Mat. Sci. Eng. A300 (2001) 254.

[24] P. Li, Z.F. Zhang, S.X. Li, Z.G. Wang. Mat. Sci. Eng. A527 (2010) 2305. 


\section{Figure captions}

Fig. 1 Inverse pole figure showing the normal directions of grains in the annealed sheet from a region mapped by EBSD.

Fig. 2 TEM micrographs showing example microstructures seen in the compressed sample: (a) cell structure (Type 2 microstructure), (b) extended planar boundaries near-parallel to a $\{111\}$ trace (Type 1 microstructure); and (c) extended planar boundaries not close to a $\{111\}$ trace (Type 3 microstructure). The compression axis directions for these three grains are shown in (d). Fig. 3 TEM micrographs showing example microstructures of $\mathrm{Al}$ (99.99\% purity) deformed by tension to strain of $\varepsilon=0.14$ : (a) Type 2 microstructure; (b) Type 1 microstructure, and (c) Type 3 microstructure.

Figure 4: Dependence of dislocation boundary type on grain orientation during (a) compression; (b) tension (from Ref. [21]). 
Click here to download high resolution image

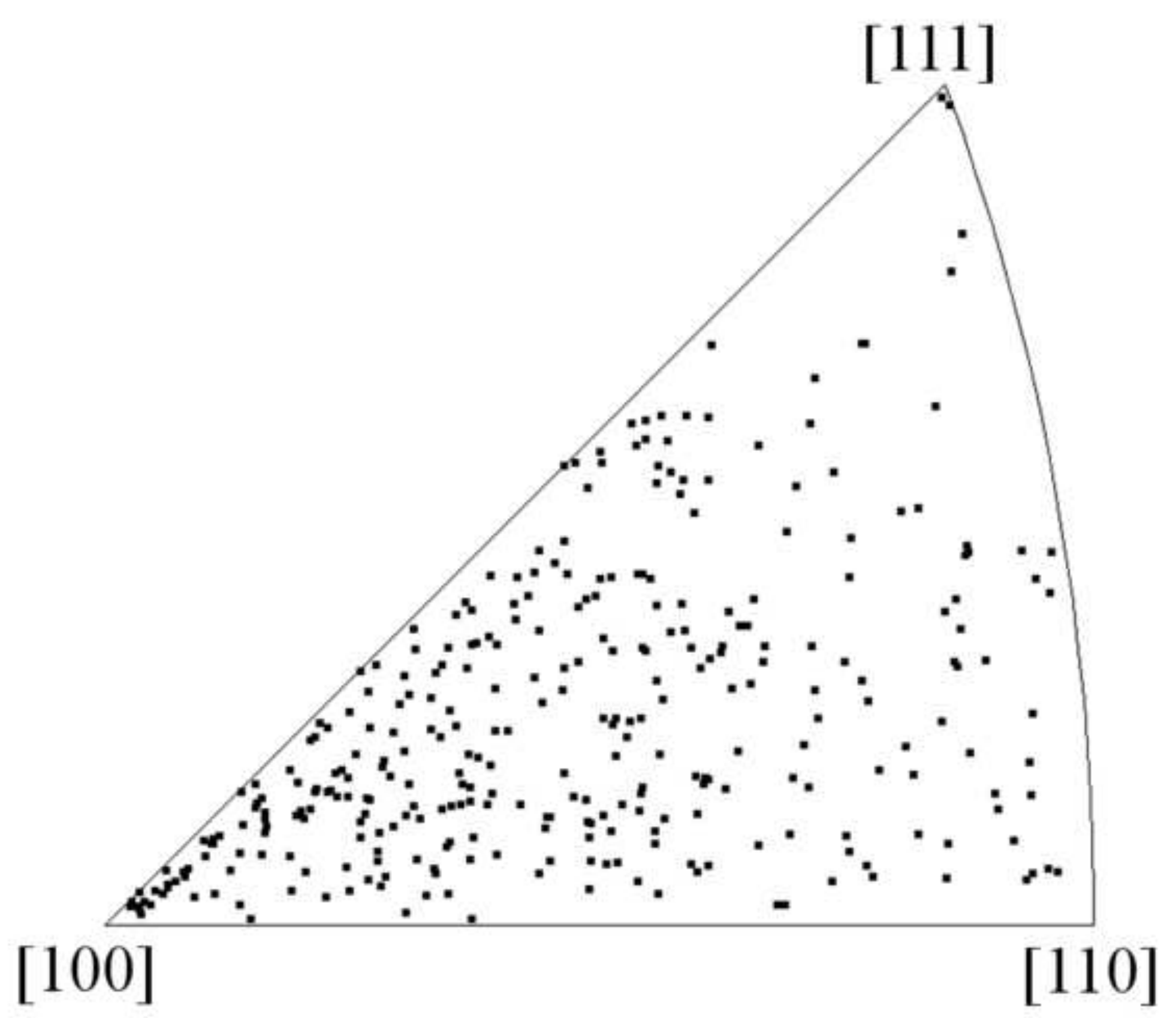


Click here to download high resolution image

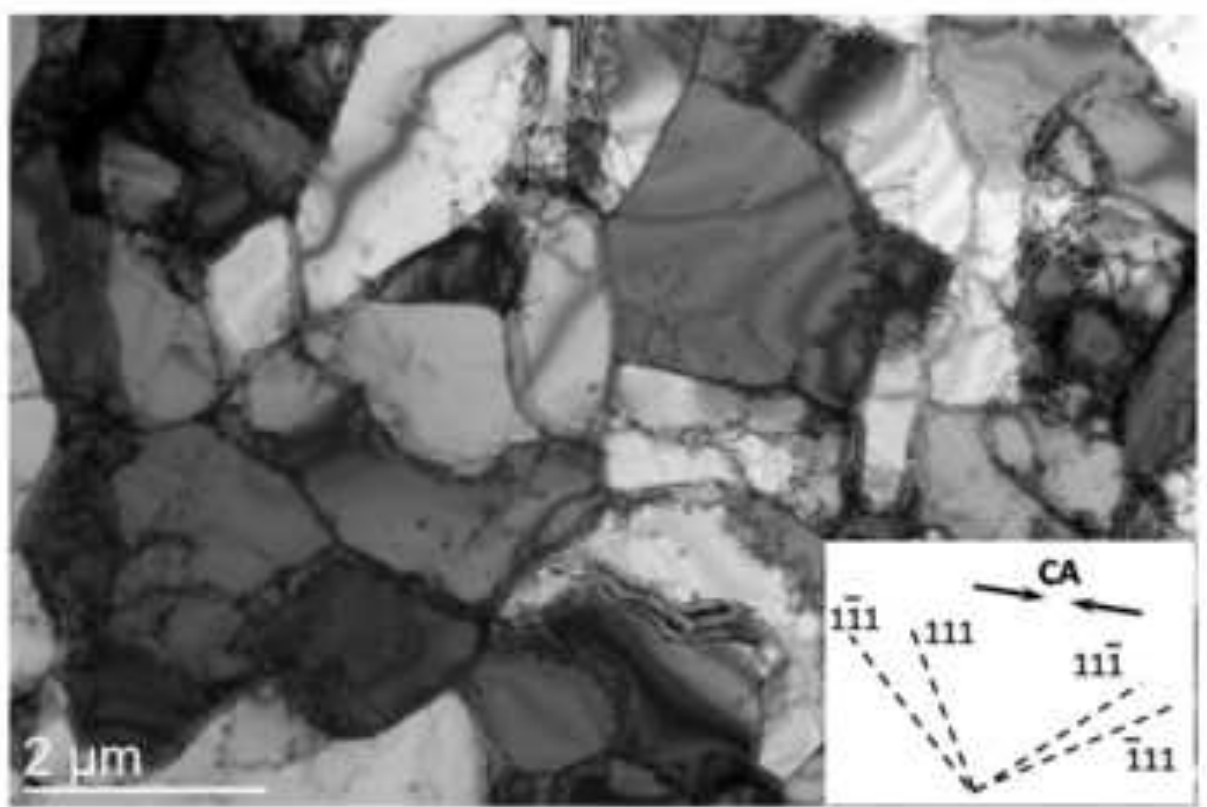

(a)

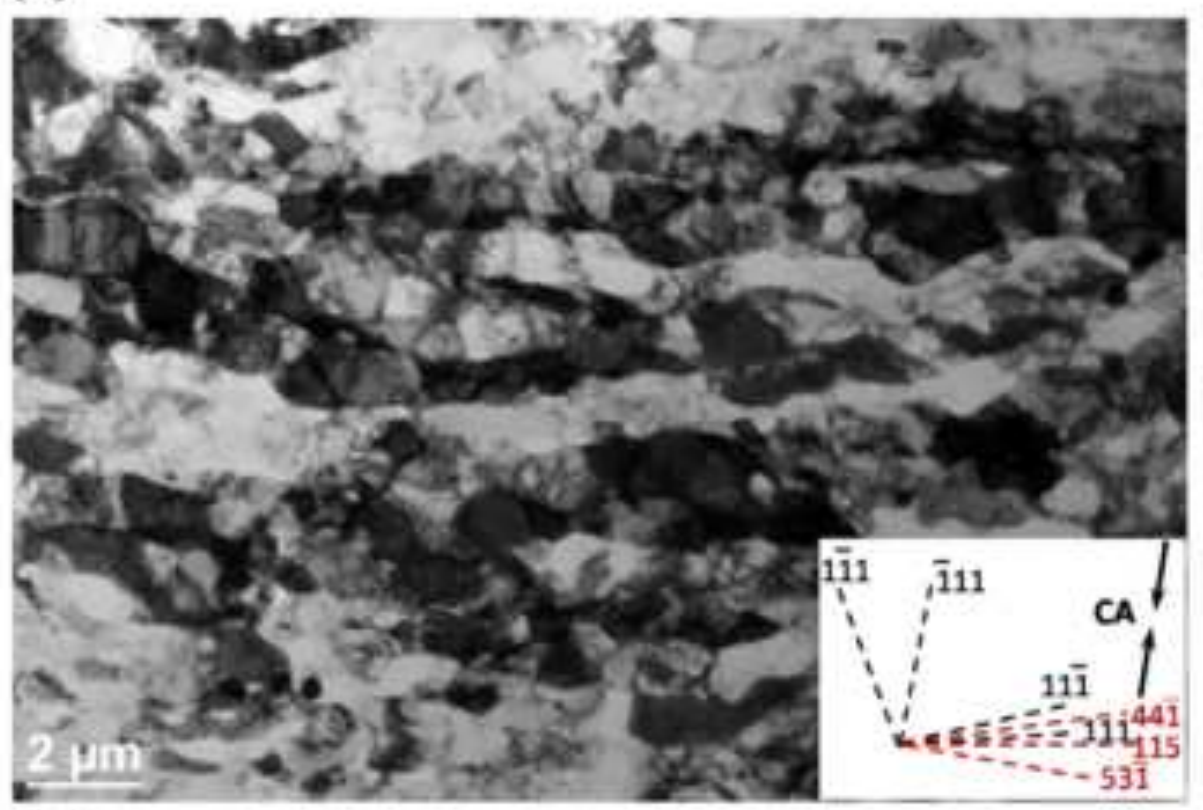

(c)

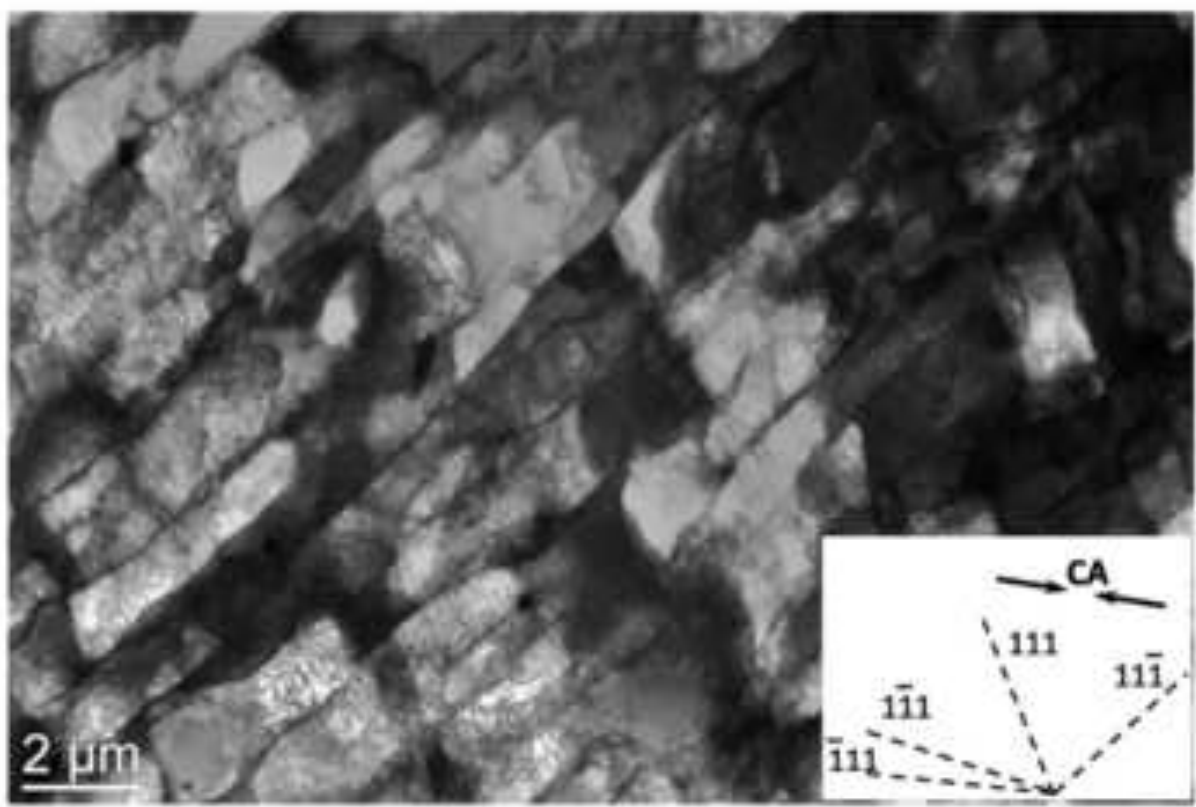

(b)

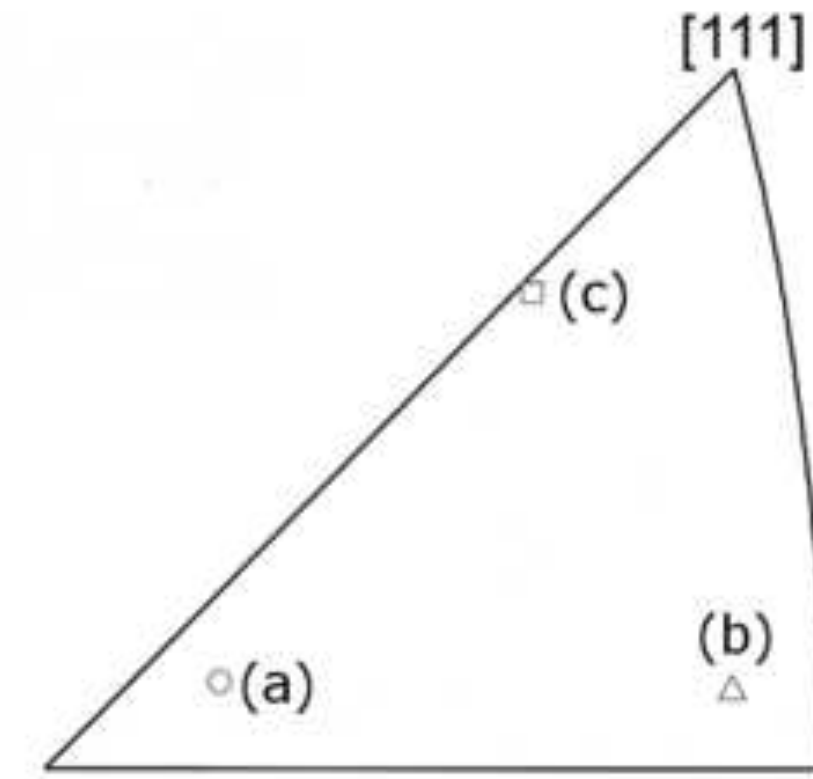

(d) [100] 
Click here to download high resolution image

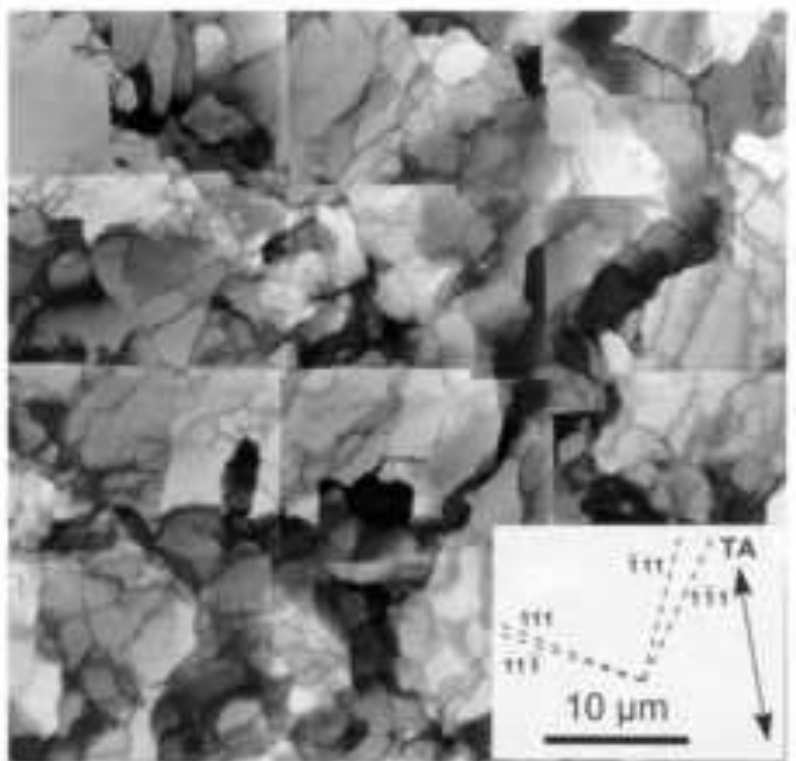

(a)

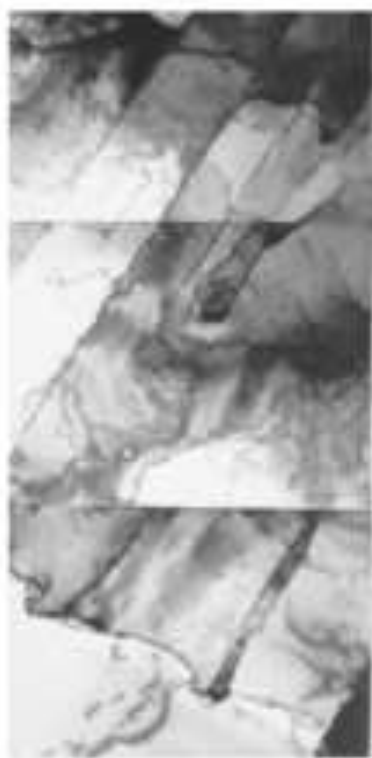

(b)

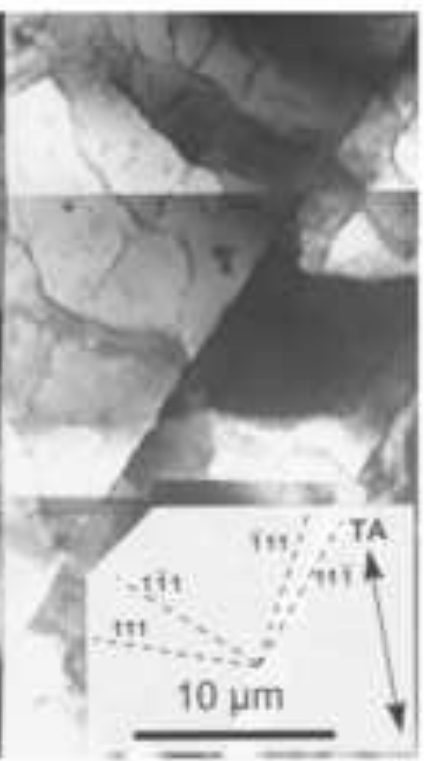

(c)

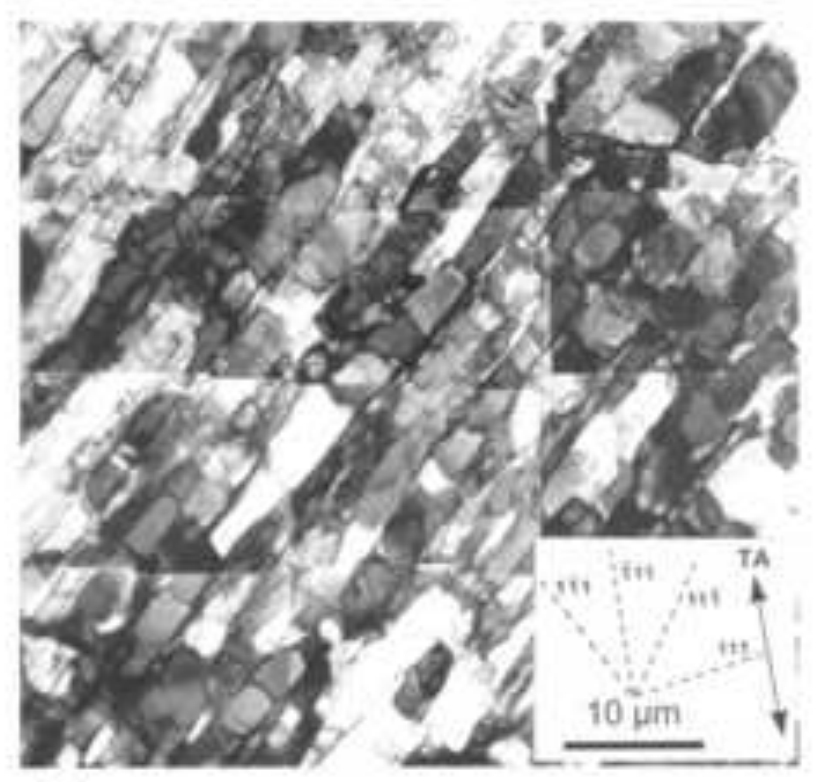




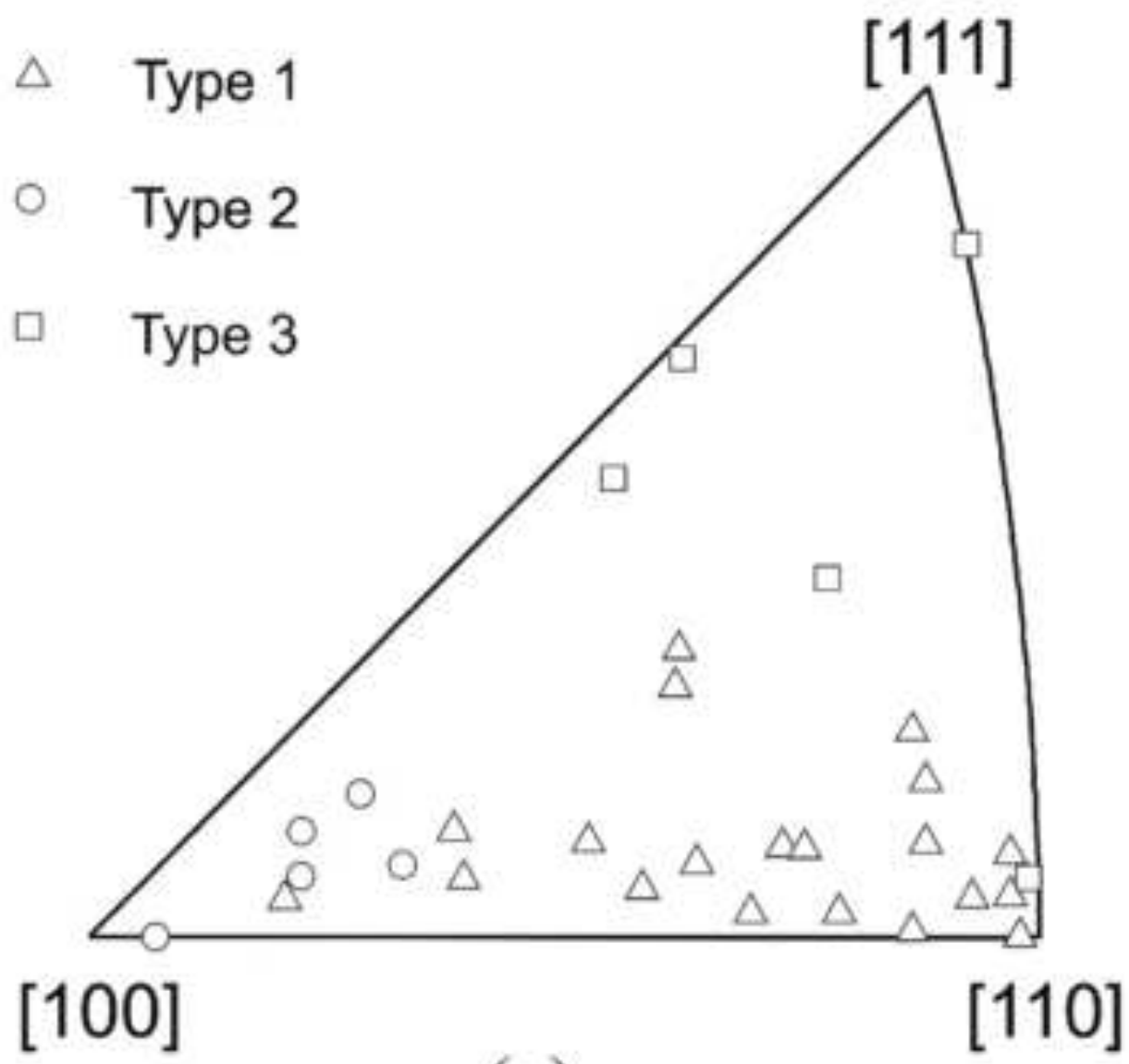

(a) $\triangle \quad$ Type 1

- Type 2

ㅁ Type 3

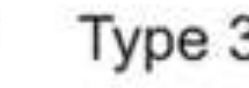

[111]

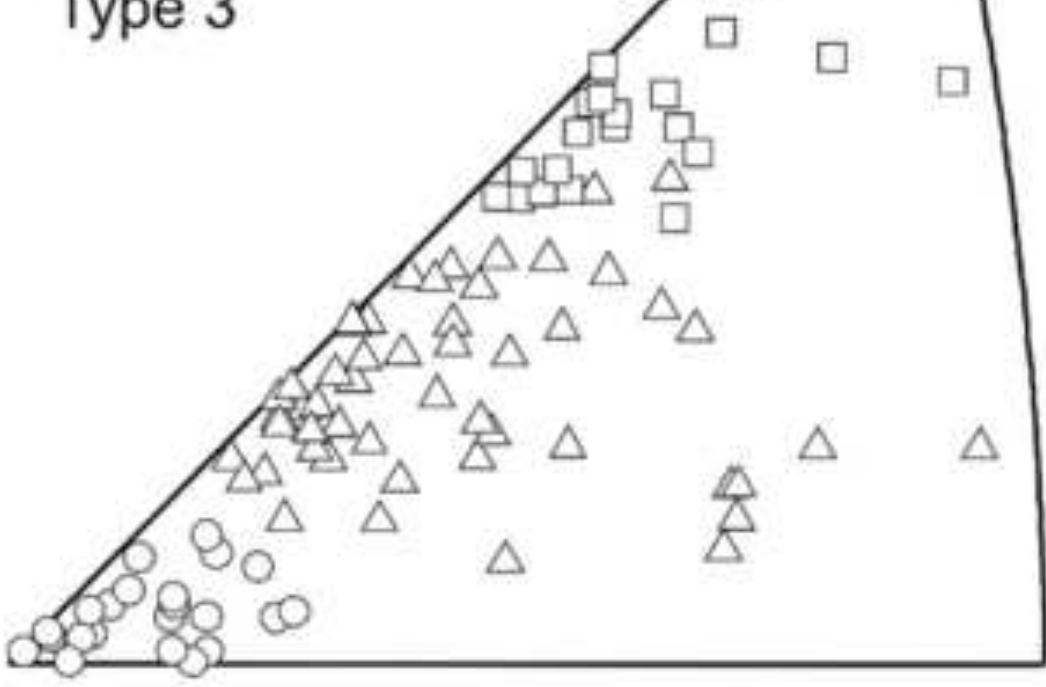

[100]

(b) 